\title{
The Role of the Laboratory to Protect Patient Health and Health Savings
}

\author{
Roberto Verna* \\ Professor of Clinical Pathology Sapienza University of Rome, Italy \\ *Corresponding author: Roberto Verna, Professor of Clinical Pathology Sapienza University of Rome, Italy
}

\begin{tabular}{lll}
\hline ARTICLE INFO & & ABSTRACT \\
$\begin{array}{l}\text { Received: } \\
\text { Published: March 07, } 2019\end{array}$ & & $\begin{array}{l}\text { Citation: Roberto Verna. The Role of the Laboratory to Protect Patient Health and Health } \\
\text { Savings. Biomed J Sci \& Tech Res 16(1)-2019. BJSTR. MS.ID.002790. }\end{array}$ \\
\hline
\end{tabular}

\section{Opinion}

At the World Health Assembly, held in January in Geneva, all the Nations have taken into consideration the role of vaccines and of the access to cure as a paradigm of how financial resources should be re modulated. A very important awareness in itself, but unfortunately no one has evidenced the fundamental role of laboratory and in particular of early diagnosis, in the decrease of expense for the National Health System. At least in Italy, the expense for laboratory tests is around $2-3 \%$ of the overall health expenditure, but the expense for un appropriate recoveries reaches 15\%. According to the spending review hypothesized by the government, it was necessary to retrain social health spending, making cuts to costs and also to staff, but what the medical world and patients demand is that the quality of the protection of patient's health should not be changed. The role of the laboratory to protect patient health and allow health savings means to combine the protection of patients' health with the savings needs of the NHS through the improvement of quality in laboratories. Clinical diagnostics are largely based on laboratory diagnostics: over $70 \%$ of diagnoses are built on laboratory data. We reach almost $100 \%$ in Microbiology and Virology.

Today, advanced molecular diagnostics are crucial for the early identification of a large number of diseases and it is obvious that in most cases, early diagnosis not only greatly decreases the patient's risk by contributing to faster recovery but is also a source of safe savings because it avoids a large number of complications that arise as a result of a late diagnosis. Through the research in the field of pharmacogenetics we have come to the personalized medicine for a more and more defined therapy on the needs of the patient, so much so that nowadays we talk about precision medicine. The laboratory is therefore a jewel for clinical diagnostics but, like all jewels, has its costs. But not even so much; but the current necessity is that nothing can cost without making results. Unfortunately, no one takes into consideration the fact that the cost of laboratory tests is infinitesimal compared to the enormous savings that they can determine in defining the correct therapeutic treatment of a subject. In Italy, the cost of laboratory tests is only the $2-3 \%$ of the health expenditure, while the cost of un appropriate recoveries reaches up to $15 \%$. The limit of the clinical laboratory lies in the lack of awareness that the citizen - and with him also a large part of those who manage the economic flows - has about the usefulness of the laboratory, because this is considered a service like any other, without evaluating its effectiveness. Having to undergo a therapy or a surgery, you are informed about the quality of this or that doctor, of this or that hospital; nobody, however, thinks of choosing one or the other structure on the basis of the laboratory of which it makes use. The laboratory: this stranger, we could say. Yet it should be pointed out that a reliable examination, of the cost of a few cents or at most a few euros, can save thousands of euros and, sometimes, millions.

Some time ago, the Center for Microcytemia in Rome, active since 1960, has been closed. The prevention carried out by the Center, practically eliminating thalassemia in the Region, has led to savings of around 10 million euros per year; now, its closure will lead in a few years, thanks also to the considerable migratory flows, to a strong recovery of the pathology, with huge health costs. At present, managers and politics is trying to reduce the cost of 
laboratory tests both by means of linear cuts, without an assessment of diagnostic appropriateness, and by reducing the laboratories and staff involved, with the creation of vast areas, trusting in the savings determined by the scale economy. But this does not guarantee the desired savings, because the scale economy is accompanied by an increase in costs determined by transport needs and a reduction in quality determined by the increase in the time for time and often the need to repeat the test for the sample deterioration. The errors in the "preanalytical phase" (over $60 \%$ of the total) is what is put at greater risk in large areas, where the collection centers are also one hundred kilometers from the place where the analysis.

Problems of storage and transport of samples and consequent need of having to repeat the exams or, worse, to give inadequate

\section{ISSN: 2574-1241}

DOI: 10.26717/BJSTR.2019.16.002790

Roberto Verna. Biomed J Sci \& Tech Res

This work is licensed under Creative

Commons Attribution 4.0 License

Submission Link: https://biomedres.us/submit-manuscript.php answers, would increase and not reduce costs. Furthermore, the choice might make sense if such mega laboratories were located within large hospitals, while they are typically cathedrals in the desert, easy prey to multinational corporations without the primary health objective. An efficient training and a good professional skill are of pivotal importance to assess the value of the laboratory. It is important that clinicians consult laboratorists for the definition of the correct panel of tests to run. Clinicians are not bound to know all the possibilities of the laboratory and cannot know what the real usefulness of many tests is; so, a correct communication between clinicians and laboratorists may lead to avoid unnecessary tests and non to skip the necessary ones. This kind of approach will lead, to obtain an informative response and a great savings in public health.

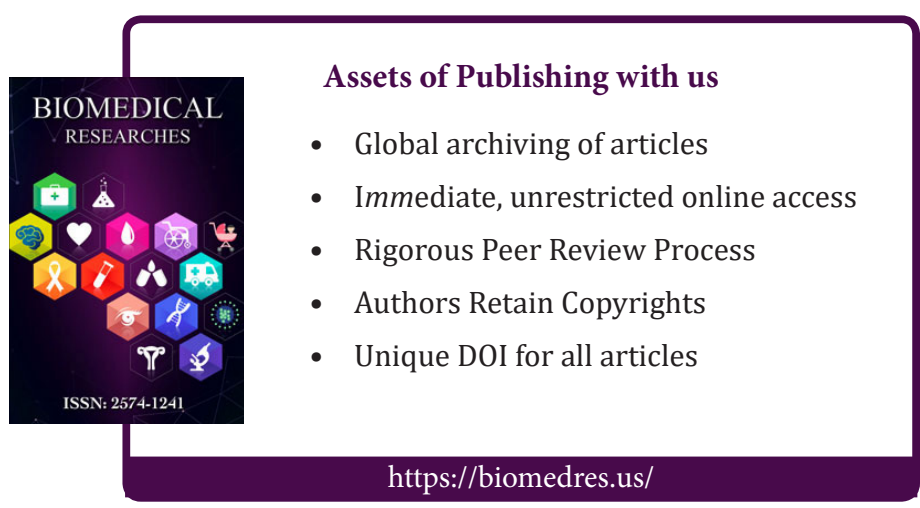

